\title{
The Pandemic Preferred User
}

\author{
Katie Ellis, Kai-Ti Kao, Tim Pittman
}

The technology departments of Australian universities have a model user for their technology offerings. Throughout this paper, we describe this construct as the "preferred user." Preferred users generally represent what some perceive to be the main cohort of students, who study full time, have access to good technology and the time and capacity to solve their own technology problems. Kao and her colleagues profile the preferred user student as one who is studying full time, financially stable, able-bodied, and neurotypical (Kao et al. 2020). The construct of the preferred user does not reflect the struggle other student groups, including people with disability, can have with using university technologies. Constructing the preferred user as the normative position becomes disabling to marginalized and excluded students, who make up an increasingly large proportion of the student body. But there is hope, and it comes in the form of lessons we've learned in higher education since the COVID-19 pandemic began. As people stayed home and students became totally remote learners, we learned that technology modifications for people with disability can benefit all users. The pandemic experience has made it clear for disability activists and faculty staff that it is time for the preferred-user profile of our universities to change. It is time the preferred user looks more like the non-preferred or disabled user, so technology systems can be inclusive to all user groups, not just the "preferred" or normative students.

Since the 1990s, Australian higher education equity policy has maintained an aspiration towards proportional representation. While proportional representation is a political concept when used in educational policy, the goal is to ensure the make-up of a student population reflects society as a whole. As stated in a 1990 discussion paper entitled A Fair Chance for All (Department of Employment Education and Training, 1990, p. 2), the overall objective for equity in higher education:

... is to ensure that Australians from all groups in society have the opportunity to participate successfully in higher education. This will be achieved by changing the balance of the student population to reflect more closely the composition of society as a whole.

The experience of university students with disability differs from non-disabled or "typical" students because of additional structural, attitudinal and physical or digital barriers (Moriña, López-Gavira, \& Molina, 2017). Despite this, the number of students with disability enrolled in tertiary education is steadily increasing throughout the world (De Cesarei \& Baldaro, 2015). A university education offers people with disability the opportunity to improve their employment and participation prospects. For students with disability to be successful they may require additional support, sometimes in the form of digital technology.

As we found in our research with students with disability using digital technologies before the pandemic, digital does not always mean accessible. As one participant explained, lecturers often offer inaccessible pdfs as required reading in university-library online reserves: 
So they all go, oh everything's available on the library, but because it goes through an external website, that external website blocks for plagiarism, I can't read it. And they go that's an essential reading, it's available to everyone, it's on the Internet. I can't read it. The lecturers have no idea what I'm talking about, no matter how many times you tell them, I actually can't read that part because if you cannot copy it and paste it, the text to speech readers can't read it. (McRae, Ellis, \& Kent, 2018)

In this example, preventing students from copying-and-pasting the document, therefore potentially preventing plagiarism, is valued above providing access to students that rely on screen-reading technology. We imagine that many lecturers likewise followed this strategy when rapidly moving their units online during COVID-19. An article published on Inside Higher Ed expressed concern for students with disability in the rush to online learning prompted by COVID-19:

Students who are deaf or hard of hearing, have low vision or are blind, those with learning disorders such as attention deficit hyperactivity disorder or a physical disability that requires use of a computer keyboard instead of a mouse, students with mental illnesses or various other challenges, have been put on the backburner "en masse," as instructors scramble to transfer two months' worth of teaching content to a digital format (Anderson, 2020).

These accessibility issues are exacerbated because of forced moves to online but are not unique to our experience of education during the pandemic. These issues are instead a continuation of the difficulties always faced by this cohort. This paper draws on critical disability studies to offer a conceptual and theoretical analysis of a deeply problematic aspect of the rapid move to online education in response to COVID-19: the reliance of notions of the preferred user. The preferred user is simply the type of person technology creators or institutions envision using their product or service. Within critical disability studies the preferred user is often recognized as white, male, and able bodied (see Ellcessor, 2016). In other words, the preferred user often excludes people with disability and other forms of disadvantage.

We begin by drawing on the social model of disability to offer a redefinition of disability as located in social practices before reflecting on how education can be redesigned using digital technologies to be more accessible for students with disability. The paper then introduces the historical disconnect between students, staff, and support services in the university context before considering the ways some Australian students with disability are provided digital devices as an academic accommodation. Following this, specific issues for students with disability studying online are examined. A key site of exclusion in this context is the notion of the preferred user, an issue we examine with reference to both university operations before and during the COVID19 pandemic. We chart the ways these already existing issues have been exacerbated by the COVID-19 pandemic and the opportunities that have also arisen, focusing on how captioning as an accessibility feature is also viewed as a vital learning tool by online students. Finally, while the forced shift to online learning during this pandemic has the ideal potential to accommodate "non-preferred" users, the actual roll out and delivery of online learning is still defaulting to modes that are both difficult and challenging, and in many cases exacerbates existing issues and inequalities. We conclude with suggestions about how a consideration of the non-preferred user might actually be the preferred approach for all.

\section{(Re)defining Disability}

In the last two decades disability has moved from the medical domain into rights-based discussions. With the adoption of the United Nations Convention of the Rights of Persons with Disability (CRPD) by 180 countries, access to education, along with a number of other sites of social inclusion, has been recognized as a human right. According to article 24, state parties 
should:

ensure that persons with disabilities are able to access general tertiary education, vocational training, adult education and lifelong learning without discrimination and on an equal basis with others. To this end, State Parties shall ensure that reasonable accommodation is provided to persons with disabilities. (United Nations, 2006)

The CRPD also foregrounds the importance of digital rights and the use of digital technologies to enable 'persons with disabilities to fully enjoy all human rights and fundamental freedoms' (Preamble to United Nations, 2006). For many university students with disability, digital technologies are a key site of support and reasonable adjustment. However as we discuss in this essay, this is not always a straightforward notion, there are a number of factors at play that disable students who have an impairment.

In using the terms disability and impairment in this way, we draw on the social model of disability, a framework developed in the UK in the 1970s that posits that disability is the social reaction to the effects of impairment (Finkelstein, 1975). According to the social model, disability is the restriction of activity imposed on top of people who have an impairment (Oliver, 1996). This model is effective in shifting the problem of disability from an individual's body and locates it within a society constructed to exclude that particular body. Society can, therefore, be redesigned to be more inclusive. While this paper proceeds from a social model of disability, we have elected to use the terminology students with disability as it is the established best practice terminology in Australia, the country in which we live and work.

Through the construct of the preferred student, universities have excluded students with disability; however, its important too to acknowledge the advances that have been made. For example, a number of specialised technologies exist to compensate for the effects of impairment in an educational context such as braille displays, voice recognition, teletext communication and use of vibrations (for a full list see Raja, 2016, pp. 8-9). In addition to these technologies specifically designed for the disability community, a number of inclusively designed mainstream digital technologies also offer flexibility and inclusion to students with disability and those without such as:

- Ebook text size can be increased depending on the student's needs. Images can be read aloud through tagging tools. Access to print-fidelity page images can mean students can follow along in lectures, page by page.

- Online learning management systems allow students to study anywhere, anytime.

- Screen readers and dictation software allow students to access course materials and complete assignments.

- Smartphones enable app-based and learning-specific modifications based on disability and personal use parameters, including touchscreen functionality, geolocation for campus navigation, and realtime updates that affect online and offline accessibility.

This list contains technology that has been designed according to the principles of inclusive design. Inclusive design refers to the design of products and or services that can be used by the majority of the population without the need for special adaptation or design. Inclusive design designs for edge users or non preferred users in order to capture the broadest possible user base. Inclusively designed digital technologies offer students with disability increased flexibility and accessibility of learning, and greater control over the disclosure of their disability to both fellow students and teaching staff, a feature highly valued by this cohort (Roberts, Crittenden, \& Crittenden, 2011). 


\section{Disconnect between Students, Staff and Support Services}

Students with disability have long faced a number of difficulties in higher education. Despite meeting the same entrance requirements as students without disability, fewer students with disability successfully complete their degrees and graduate (Australian Disability Clearinghouse on Education and Training, 2019; Easterbrook et al., 2019; Fleming, Oertle, \& Plotner, 2017). This is in spite of the increased presence of disability support services in universities and greater efforts to raise awareness of disability more generally. Some of these difficulties begin from the point of enrolling in a higher education course. In order to receive approved, systemic support, universities generally require students to disclose themselves as disabled. The less inclusive the built, social and technological design of the university, the greater the need for students to disclose. This often involves significant paperwork and bureaucracy, not to mention emotional cost. Processes require students to justify why they are worthy of accommodations, which can result in the student feeling both disempowered and defined by the label of their disability (Adefila, Broughan, Phimister, \& Opie, 2020; Langørgen \& Magnus, 2018). This process is premised on the assumption that the student is already aware of their disability and has a diagnosis, that they are capable of and willing to self-advocate, and that they are aware of the various accommodations and assistance they are entitled to (Fleming, Plotner, et al. 2017; Langørgen and Magnus 2018). This is also an approach that focuses attention on providing accommodations for the student's disability, thus reinforcing a normative non-disabled experience of higher education. An inclusive design approach by comparison, recognizes that not all students fit into the preferred user construction and an incorporation of digital flexibility benefits the entire student cohort.

Students also report that despite negotiating appropriate supports with the disability office, the disabling attitudes of individual teaching staff can have a negative impact, for example, on whether they feel comfortable using assistive technology in class or if course content is made available in an accessible digital format (McRae et al., 2018). These attitudes are no secret academics have gone as far to publish opinion pieces on why students with disability should not be given accommodations (Pardy, 2017). The notion that people with disability gain advantage via deception or exaggerating the effects of their impairment has a long history and has been examined in depth by social model disability theorists (Barnes, 1992). While a full discussion of the impacts of individual professors' attitudes is outside the scope of this paper, we mention it here to highlight the systemic nature of the issue.

Although there is evidence that students with disability who feel well supported tend to perform better in higher education, disability support services often struggle with inadequate resourcing leading to the proliferation of cookie-cutter support plans that lack the personalization required to meet students' needs (Fleming, Oertle, et al., 2017, pp. 314-315). Teachers working with such support plans have little awareness of the complexities of the student's disability or understanding of their individual needs (Kao et al., 2020). As mentioned above, staff can sometimes be ambivalent towards the needs of students with disability, even prior to the pandemic, "triggered by conflicting roles and values, unclear outcome measures to evaluate the students, a lack of knowledge of how to accommodate, time constraints, insufficient institutional support, as well as a lack of openness regarding students with disabilities" (Langørgen \& Magnus, 2018). These can lead to negative experiences that leave students reluctant to further self-advocate for the support they require (Fleming, Oertle, et al., 2017; Fleming, Plotner, \& Oertle, 2017).

Further, there are also difficulties with institutional approaches towards students with disability, which too often tend to reflect limited perceptions of disability. Efforts to address accessibility issues at universities have primarily focused on physical access to campus spaces and facilities (Bialka, 2018). This approach not only centers focus on visible disabilities, limiting awareness of the prevalence and range of non-visible disabilities among the student cohort, but also ignores the educational experience itself by focusing on access to spaces (Kao, Tay, \& Woods, 2020). By requiring students to self-advocate and negotiate complex bureaucratic processes for what are often inadequate accommodations, institutions appear to be oblivious to the fact they 
are forcing students with disability to divert their time and resources away from their education itself. A study of Canadian higher education institutions indicated that disability service providers wished for many improvements relating to accessible information and communications technologies (ICT) (Fichten, Asuncion, Robillard, Fossey, \& Barile, 2003). Seventeen years later, accessible ICT remains a significant issue for disability support in Australian universities and digital technologies can be both enabling and disabling (Ellis \& Kent, 2011; Goggin \& Newell, 2003), particularly when intersectionality is considered (Alper, 2017; Ellcessor, 2016).

\section{Australian Students with Disability ICT Use}

Australian students with disability are sometimes provided with digital devices as part of their academic accommodations. For example, in one study of students with autism in higher education in Australia, a student discussed being provided with a computer to help with notetaking and to avoid handwriting legibility issues (Cai \& Richdale, 2015, p. 36). However, there can be issues with the provision of ICT in these situations as students are often only permitted to use the devices for narrow purposes (Alper, 2017), despite the fact that non-specialised software and digital devices can actually be the most commonly used and most helpful assistance for students with disability (Fichten et al., 2013; Heiman, Fichten, Olenik-Shemesh, Keshet, \& Jorgensen, 2017).

For example, the simplest ICTs can have significant benefits for students, including allowing a greater degree of self-determined learning. Furthermore, where ICT conforms to the principles of universal design, the benefits can be extensive for both students with disability as well as those students without (Rose, Harbour, Johnston, Daley, \& Abarbanell, 2006). Heiman et al. (2017) examined student perceptions of ICT used by teaching staff in a traditional, face-to-face higher education institute in Canada and a distance or blended learning higher education institute in Israel. The researchers found only partial support for their hypothesis that students with learning disabilities across both institutions would use more ICTs compared to students without learning disabilities. All students found ICTs useful - "most of the students (with and without disabilities) are using the computers for assignments, including grammar and spell-checking, graphical organizers, calendars, etc., which were considered as accommodation tools for students with disabilities" (Heiman et al., 2017, p. 2738).

Furthermore, when students are provided with properly accessible digital formats for learning materials, they can customize their use without having to request specific accommodations (Belch, 2004, pp. 12-13). This has the additional benefit of assisting students with undisclosed or not formally diagnosed disabilities who would otherwise not receive formal accommodations. Previous studies have shown that a significant number of students, particularly when studying online, will choose not to disclose that they have a disability (Kent, 2015; Roberts et al., 2011).

\section{Specific Issues for Students with Disability Studying Online}

Given that online delivery of higher education courses is increasingly common, it is also worth exploring whether there are factors that particularly influence retention of online students. According to a study by Muilenburg and Berge, some aspects of the technological experience such as technical skills, cost and access to the internet, and technical issues, were significant barriers to student success, although they were not as significant as non-technological aspects of the online experience such as administrative/instructor issues, social interactions, academic skills, learner motivation, and time and support for studies (Muilenburg \& Berge, 2005, p. 38). Although this may seem as though non-technical aspects of online learning are more significant factors, all of these factors can be ultimately mediated through ICT in an online learning environment. However, the research also shows that a one-size-fits-all approach cannot be taken. A 2016 study into students 
with disability studying fully online through Open Universities Australia found that different impairments had different needs - students with vision- and hearing-related impairments had the most problems with learning technologies, while those with mobility impairments and mental illness were impacted more through non-technical factors (Kent, 2016).

In order to address some of these issues, a Quebecois study by Fichten et al. (2013) involved compiling a list of ICTs that experts believed would benefit college students with learning disabilities and then asking those students which ICTs they actually used. The researchers found key discrepancies between the expert recommendations and student realities. Firstly, a lot of ICTs experts thought would benefit students with learning disabilities were not actually used by those students. Secondly, "students reported using smartphones/cell phones/iPods, MP3 players, and instant messaging as productivity tools; these are general-use ICTs that the experts did not mention. Clearly, students and experts need to share their perspectives about ICTs that could be useful" (Fichten et al., 2013, pp. 184-185).

\section{The Preferred User Student}

The concept of the preferred user, as explained by Elizabeth Ellcessor, "reflect idealized access conditions, which are normalized as defaults around which policies and technologies are regularly formed" (Ellcessor 2016, p.77). She argues that perceptions of the preferred user invariably default to able-bodied notions of ability and access, for example, "at the physical, embodied level of use, preferred user positions encourage sitting — at a desk, with a laptop, the user's body folded and seated-and gazing at a lit screen, using fine motor skills to type or control a mouse" (Ellcessor 2016, p.76).

Even before the COVID-19 pandemic, higher education largely operated with an assumption of a "preferred user" student. In exploring a parallel concept of the "ideal student," Wong and Chiu explain that while assumptions of what constitutes such an ideal student may vary according to the context of the institution or discipline, there are certain characteristics that are broadly homogenous and are both structurally and unconsciously privileged within higher education (Wong \& Chiu, 2019). While such thinking may operate at a distant and abstract level, it nonetheless perpetuates a culture of normalcy within higher education that "reproduces thinking that non-traditional students are non-white, working-class and/or disabled" (Madriaga, Hanson, Kay, \& Walker, 2011, p. 901). Such perceptions of an ideal student or preferred user are rarely explicitly discussed or even acknowledged by higher education institutions as they run counter to the now widely accepted equality agenda: "that ability should be able to access opportunity regardless of circumstance" (Brink, 2009, p. 4). A more cynical reading of this lack is that open discussions of the preferred user student are avoided as they could negatively impact an institution's position within a competitive student market. The problem with this though, as Wong and Chiu explain, is that they nonetheless pervade and influence the way higher education operates and such "unspoken assumptions and expectations of students offer limited guidance to develop as university students, especially for those from non-traditional backgrounds"(Wong \& Chiu, 2019, p. 9) . By avoiding open discussions about the preferred user student, we are enabling a higher education system that focuses on getting students in the door, but once in are expected to conform to a system that provides inadequate recognition or allowance for their difference. A better and more open understanding of how assumptions of the preferred user operate within the higher education context will play a significant role in enabling an educational experience that is truly universal and accessible.

Speaking in reference to media generally, Ellcessor explains that shifts to newer platforms where issues of universal access have not been fully considered, presume "a default abled user" (p. 31), and thus can work to further disable people who had previously established other forms of access (p. 31). In the case of the forced shift to online learning prompted by the COVID-19 pandemic, some students with disability lost access to their learning that had previously been 
supplemented by accommodations such as in-class assistance, technology, or support services. This loss worked to further situate them as disabled.

While the COVID-19 pandemic exacerbated issues for students with a disability, it also created difficulties for other students who did not fit the preferred user student default: students who were studying part-time while working, those who had significant carer responsibilities, international students who lost their jobs and lacked access to government welfare, students with English as a second language, and international students unable to return home.

\section{Captions for All Users Broadens the Scope of Digital Disability Access}

While the COVID-19 experience has presented issues, there are also opportunities. For example, accessibility features such as captioning for people with disability, or non-preferred users, have been beneficial to all students trying to work from home and juggling competing priorities. This was the main finding of a study we conducted before COVID-19 and the finding took on greater resonance as large number of students found themselves studying from home and handling competing domestic priorities.

In order to better evaluate the potential uses of captions among an entire student population, we had offered captions to the mainstream student population of all Curtin University students enrolled in 11 digital and social media, screen arts and fine art units offered in study periods 3 and 4 in 2018. These students were invited, via email, to participate in a short online interview to discuss their understandings of captions and reflect on the ways they could potentially be used in their future teaching and learning. A total of 53 students from the 22 units offered over the two study periods participated in these interviews. Some students participating in the interviews self-identified as being from at-risk groups, including being hard of hearing, having English as an additional language, and having sensory-processing difficulties.

The student interview was designed to identify current and anticipated expectations regarding captions as a pedagogical tool. Questions were grouped into four main categories - students' current usage of captions in online lectures, the potential benefits — and therefore the likelihood of using captions - if they were made available in other units, their expectations regarding caption accuracy, and the impacts of (in)accurate captions.

Several prevalent themes and experiences regarding participants' views on the educational benefits of captioned lectures became apparent across the interviews. We found that students with and without a disability have diverse learning styles and used captions alongside a variety of other learning tools in ways that suit their visual, auditory, and kinaesthetic approaches to learning. These students expected captions to be available in online lectures because they are so widely available and embraced in entertainment media (see Farley, 2017; Kehe, 2018). These students also multitask while accessing lectures, and therefore see captions as a way to retain focus and improve clarity. They also believed that the provision of captions improved the quality of teaching in an online environment. On a practical level, these students used captions for insight into the correct spelling of technical words when they might be unable to ask a lecturer during an in-person class.

They expect the university to provide any tool that may enhance their learning and believed captions should be accurate. The students we spoke to were dealing with complex visual and audio material in online lectures. They stated they not only needed to know what the lecturer was saying, but were also simultaneously trying to read the slides, make the connection between the content on the slides and what the lecturer was saying, interpret the lecturer's body language and movement, and decipher all of this in the context of the course itself.

These two quotes are indicative of the kinds of comments students made about captions being a vital teaching and learning tool:

As I am an online student, all of my lectures are online. I sometimes view them multiple times. I will stop 
the lectures if required while I am taking notes, and sometimes replay sections if I have lost my focus, missed the main points or have difficulty understanding what the lecturer is saying. I usually watch/ listen to the lectures in our home office which is separated from the rest of the family, however, I can be interrupted by the teenagers living in the house if they want attention.

[I prefer] captions over sounds. With sound/audio, some accents can be hard to distinguish words. Some lecturers have monotone voices and can make a subject quite uninspiring. Audio is harder to use at night while [my] husband is sleeping, and I want to study.

During the pandemic, all students were online students who were potentially experiencing these or similar issues. While the forced shift to online learning during this pandemic had the ideal potential to accommodate "non-preferred" users, the actual roll-out and delivery of online learning was still defaulting to modes that were both difficult and challenging, and in many cases exacerbating existing issues and inequalities. Yet the example of captions shows how a consideration of the non-preferred user might actually be the preferred approach for all.

\section{Conclusion}

As COVID-19 was declared a pandemic, universities acted quickly to move their core business of teaching and research online. Classes shifted to platforms such as Zoom, Webex, Collaborate, and Microsoft Teams and teachers and students alike were expected to adapt. And they did. While there has been much discussion of the unpaid labor involved in making this shift and the difficulties inherent in merging work, study, and domestic life, there has been little acknowledgment or analysis of inherent notions of the preferred user in this rapid shift to technology.

Within the context of higher education, the preferred user student can be identified as one who is studying full time, financially stable, able-bodied, and neurotypical (Kao et al., 2020). In other words, we default to assuming that students are: able to prioritize their studies as their main focus without other significant demands on their time; that they have a secure source of income sufficient to meet their living needs and otherwise free up their time to focus on their studies; that they can easily access the spaces and resources required for their studies and participate in required activities; and that they are able to confidently engage, communicate, and cope with new and complex social situations. Any variations to this default assumption are dealt with via relevant accommodations by the university. For example: if the student has work or carer responsibilities, then they are encouraged to enroll in a part-time load; if the student has a mobility impairment that restricts access to certain venues, then the class is shifted to a more accessible venue. Such accommodations serve to reinforce the preferred user as the default norm for the university experience.

In light of the COVID-19 pandemic, we can also add "technologically connected" and "digitally literate" to our perceptions of the preferred user student. In the rush to move courses online, many institutions, teachers and instructors fell back on such a default assumption of their students. Not only did the shift to online learning require students have access to adequate internet services and suitable technology devices, but they further assumed that students would be sufficiently familiar with and competent in negotiating new digital scenarios such as the large and sometimes confusing online synchronous sessions that replaced face-to-face classes. This shift also highlighted the limitations of existing accommodations for students with disability. Lectures moved to online recordings without appropriate provisions for captioning, interpreters and notetakers did not always have access to webinars, class materials were not always provided in advance to allow students sufficient time to prepare, and neurodiverse students reported difficulties focusing during online synchronous class sessions (Wilson et al., 2020). Mental health issues were exacerbated by the stresses associated with the shift to online learning, which in 
turn further compounded the broader social pressures and concerns wrought by the COVID-19 pandemic more generally (Wilson et al., 2020).

While the preferred user student, as outlined in this paper, may be the default, it no longer accurately represents the reality of the 21 st-century student cohort. This is a fact that universities need to acknowledge as they look to re-establishing a sense of normalcy in the post-pandemic world. We need more inclusive methods, processes, and systems of education that will not only benefit disabled students, but the increasingly wide range of students who do not fit the preferred user student mold.

\section{Acknowledgements}

This paper draws on extensive research conducted with students with disability at Curtin University Western Australia between 2016 and 2020 including the projects Engaging with lectures online: How useful are active captions? (Ethics Approval number: RDHU-10-16); Internet of Things (Io'T) Education: Implications for Students with Disabilities (Ethics Approval number: HRE2017-0482); Digital Technologies and the Completion Rates of University students with disabilities: inclusive learning for the future (Ethics Approval number: HRE2018-0338); Capturing Captions: An audit of speech-to-text translations in Echo360 for lecture accessibility (Ethics Approval number: HRE2019-0135). 


\section{References}

Adefila, A., Broughan, C., Phimister, D., \& Opie, J. (2020). Developing an autonomous-support culture in Higher Education for disabled students. Disability and health journal, 100890-100890. doi:10.1016/j. dhjo.2020.100890

Alper, M. (2017). Giving voice : mobile communication, disability, and inequality: Cambridge, Massachusetts : MIT Press.

Anderson, G. (2020, 6 April). Accessibility Suffers During Pandemic. Retrieved from https://www. insidehighered.com/news/2020/04/06/remote -learning-shift-leaves-students-disabilities-behind

Australian Disability Clearinghouse on Education and Training. (2019). Higher Education Statistics. Retrieved from https://www.adcet.edu.au/inclusive-teaching/ understanding-disability/Higher-Education-Statistics/

Barnes, C. (1992). Disabling imagery and the media: An exploration of the principles for media representations of disabled people. Retrieved from http://www.leeds. ac.uk/disability-studies/archiveuk/Barnes/disabling\%20 imagery.pdf

Bialka, C. (2018). College Students with Disabilities Are Too Often Excluded. Retrieved from http://theconversation.com/college-students-with-disabilities-are-too-often-excluded-105027

Brink, C. (2009). "Standards Will Drop"--and Other Fears about the Equality Agenda in Higher Education. Higher Education Management and Policy, 21(1), 11. doi:10.1787/hemp-v21-art2-en

De Cesarei, A., \& Baldaro, B. (2015). Doing online research involving university students with disabilities: Methodological issues. Computers in Human Behavior, 53, 374-380. doi:10.1016/j.chb.2015.07.028

Department of Employment Education and Training. (1990). A fair chance for all. Canberra: Australian Government Printing Service.
Easterbrook, A., Bulk, L. Y., Jarus, T., Hahn, B., Ghanouni, P., Lee, M., ... Parhar, G. (2019). University gatekeepers' use of the rhetoric of citizenship to relegate the status of students with disabilities in Canada. Disability \& Society, $34(1), 1-23$. doi:10.1080/09687599.2018.150 5603

Ellcessor, E. (2016). Restricted access : media, disability, and the politics of participation: New York : New York University Press.

Ellis, K., \& Kent, M. (2011). Disability and New Media. New York: Routledge.

Farley, R. (2017, 29 July). Get Over Your Fear Of Subtitles, Please. Retrieved from https://www.refinery29.com/ tv-closed-captions-movie-subtitles-benefits

Fichten, C. S., Nguyen, M. N., King, L., Barile, M., Havel, A., Mimouni, Z., ... Asuncion, J. (2013). Information and Communication Technology Profiles of College Students with Learning Disabilities and Adequate and Very Poor Readers. Journal of Education and Learning, 2(1), 176. doi:10.5539/jel.v2n1p176

Finkelstein, V. (1975). To Deny or Not to Deny Disability. Magic Carpet, 27(1), 31-38. Retrieved from http:// www.independentliving.org/docs1/finkelstein.html

Fleming, A. R., Oertle, K. M., \& Plotner, A. J. (2017). Student Voices: Recommendations for Improving Postsecondary Experiences of Students with Disabilities. Journal of Postsecondary Education and Disability, $\underline{30}(4), 309$.

Fleming, A. R., Plotner, A. J., \& Oertle, K. M. (2017). College Students with Disabilities: The Relationship between Student Characteristics, the Academic Environment, and Performance. Journal of Postsecondary Education and Disability, 30(3), 209.

Goggin, G., \& Newell, C. (2003). Digital Disability: The social construction of Disability in New Media. Lanham: Rowman and Littlefield Publishers Inc.

Kao, K.-T., Tay, E., \& Woods, D. (2020). Accessibility and Inclusivity: Collaborative Learning and Students with Disabilities. Paper presented at the WA Teaching and Learning Forum, Joondalup Westen Australia. 
Kehe, J. (2018, 26 June). The real resason you use closed captions for everything now. Retrieved from https://www.wired.com/story/closed-captions-every where/?mbid=social_fb

Kent, M. (2015). Disability and eLearning: Opportunities and Barriers. Disability Studies Quarterly, 35(1), http:// dsq-sds.org/article/view/3815/3830.

Kent, M. (2016). Access and barriers to online education for people with disabilities. Retrieved from https:// www.ncsehe.edu.au/wp-content/uploads/2016/05/ Access-and-Barriers-to-Online-Education-for-Peoplewith-Disabilities.pdf

Langørgen, E., \& Magnus, E. (2018). 'We are just ordinary people working hard to reach our goals!' Disabled students' participation in Norwegian higher education. Disability \& Society, 33(4), 598-617. doi:10.1080/096 87599.2018.1436041

Madriaga, M., Hanson, K., Kay, H., \& Walker, A. (2011). Marking-out normalcy and disability in higher education. British Journal of Sociology of Education, 32(6), 901-920. doi:10.1080/01425692.2011.596380

McRae, L., Ellis, K., \& Kent, M. (2018). Internet of Things (IoT): Education and Technology. The relationship between education and technology for students with disabilities. Retrieved from https://www.ncsehe.edu.au/ publications/internet-of-things-iot-education-and-technology-the-relationship-between-education-and-technology-for-students-with-disabilities/

Moriña, A., López-Gavira, R., \& Molina, V. M. (2017). What if we could Imagine an Ideal University? Narratives by Students with Disabilities. International Lournal of Disability, Development and Education, 64(4),353-367. doi:10.1080/1034912X.2016.1228856

Oliver, M. (1996). Understanding disability: From theory to practice. Houndsmill, Basingstoke: Macmillan.

Pardy, B. (2017, 17 August). Bruce Pardy: Mental disabilities shouldn't be accommodated with extra time on exams. Retrieved from http://nationalpost.com/opinion/bruce-pardy-mental-disabilities-shouldnt-be-accommodated-with-extra-time-on-exams
Raja, D. S. (2016). Bridging the disability divide through digital technologies: Background Paper for the 2016 World Development Report: Digital Dividends. Retrieved from http://pubdocs.worldbank.org/ en/123481461249337484/WDR16-BP-Bridging-theDisability-Divide-through-Digital-Technology-RAJA. pdf

Roberts, J. B., Crittenden, L. A., \& Crittenden, J. C. (2011). Students with disabilities and online learning: A cross-institutional study of perceived satisfaction with accessibility compliance and services. The Internet and Higher Education, 14(4), 242-250. doi:10.1016/j. iheduc.2011.05.004

United Nations. (2006). Convention on the Rights of Persons with Disabilities. Retrieved from https:// www.un.org/development/desa/disabilities/convention-on-the-rights-of-persons-with-disabilities.html

Wong, B., \& Chiu, Y.-L. T. (2019). Exploring the concept of 'ideal' university student. Studies in Higher Education, 1-12. doi:10.1080/03075079.2019.1643302 
